\title{
Asymptomatic unilateral kidney ectopia and hypoplasia in an adult Warmblood mare
}

\author{
Natalia Siwinska, Agnieszka Zak, Malwina Słowikowska and Urszula Paslawska \\ Wroclaw University of Environmental and Life Sciences, Faculty of Veterinary Medicine, Department of Internal Medicine and Clinic of Diseases of Horses, Dogs \\ and Cats, Wroclaw, Poland
}

\begin{abstract}
Summary: This article presents the case of asymptomatic renal hypoplasia and ectopy as an incidental finding in a nine-year-old Polish Thorough-Warmblood-Mixed-Bred mare. The abnormal kidney position was initially diagnosed during the rectal examination (the left kidney was not palpable). The finding was confirmed in the transcutaneous abdominal ultrasonographic examination. The left kidney was located between the middle and lower third of the abdominal cavity in the left flank, medial to the spleen, under the L1-L2 vertebrae. It was smaller than normal, more round in shape and its inner echostructure was poorly defined. The right kidney was located anatomically and had normal dimensions. The complete blood count, serum biochemistry and complete urinalysis revealed normal urinary tract function. Congenital urinary tract defects, particularly those affecting the kidneys, are rare in horses. They are most commonly described in foals and young horses. To the authors' best knowledge, renal ectopy has not been described in horses, while bilateral renal hypoplasia has been described in four horses with signs of kidney failure. Renal ectopy is a congenital anomaly characterised by abnormal organ location. Studies suggest that a developmental anomaly affecting one kidney is often accompanied by other disorders. In this case, renal ectopy was accompanied by renal hypoplasia, associated with incomplete organ development. The cause of congenital urinary tract disorders has not been fully determined. It is speculated that teratogenic drugs used either during pregnancy or to treat intrapartum uterus infections or systemic infections may result in offspring urinary tract anomalies. Due to the fact that the ultrasonographic findings of many renal pathological deformations are unspecific, a renal biopsy and histopathologic assessment of the collected specimen are needed to determine the type of structural lesion. The limitation of the presented case study is the absence of either a biopsy and histopathologic tissue examination as owner's consent could not be obtained for these procedures. Hence, the type and degree of parenchymal lesions could not be determined definitively, and the presumptive diagnosis was based on the ultrasonographic examination. In the presented mare, the incorrect kidney location and structure did not give any clinical symptoms.
\end{abstract}

Keywords: renal anomaly, congenital defect, ectopia, hypoplasia, kidney, horse

Citation: Siwinska N., Zak A., Stowikowska M., Paslawska U. (2018) Asymptomatic unilateral kidney ectopia and hypoplasia in an adult Warmblood mare. Pferdeheilkunde 34, 425-430; DOI 10.21836/PEM20180503

Correspondence: Dr. Natalia Siwinska, Department of Internal Diseases, The Faculty of Veterinary Medicine, Wroclaw University of Environmental and Life Sciences; address: Pl. Grunwaldzki 47, 50-366 Wroclaw, Lower Silesia, Poland; natalia.siwinska@upwr.edu.pl

\section{Introduction}

Congenital urinary tract defects, especially those affecting the kidneys, are rare in horses. Currently these defects have been described in breeds such as Thoroughbred, Arabian, American Quarter Horse or the Tennessee Walker (Andrews et al. 1986, Brown et al. 1988, Gilday et al. 2015, Jones et al. 1994, Naylor et al. 2009, Plummer et al. 2006, Ramirez et al. 1998, Ronen et al. 1993, Waldridge et al. 2009). Congenital renal anomalies may be embryologically classified as disorders of renal parenchymal development, disorders in embryonal migration or disorders of the urinary collecting system (Daneman and Alton 1991). Renal dysplasia is the most common anomaly and has been reported in newborn animals, foals and young adult horses with no apparent breed or sex predisposition (Brown et al. 1988, Jones et al. 1994, Naylor et al. 2009, Ramirez et al. 1998). Renal hypoplasia affecting both kidneys has been described in four horses. There is one report of a 9-month old Tennessee Walking Horse with an absent kidney and ureter (Waldridge et al. 2009). However, there are no reports of an equine ectopic kidney. Fourteen cases of an ectopic ureter have been reported (Pringle et al. 1990). Congenital anomalies are usually identified shortly after birth. Hence, most reported cases are foals or very young adult animals. The clinical signs of congenital renal anomalies depend on their type, severity and laterality. According to data from other animal species, renal hypoplasia, anomalies of shape or position are often asymptomatic and are diagnosed incidentally in adult animals (Ramanathan et al. 2016). More advanced lesions or those affecting both kidneys may be associated with unspecific clinical signs, such as poor growth or weight loss and may lead to final-stage renal failure. Thus, early diagnosis, treatment and systematic monitoring of the animal are vital in order to minimise organ damage and to avoid or delay renal failure (Ramanathan et al. 2016).

The article presents a case of asymptomatic unilateral renal hypoplasia and ectopy in an adult Polish ThoroughbredWarmblood-mixed mare. To the authors' best knowledge, there are no reports of asymptomatic horses with these two types of renal anomaly.

\section{Case report}

The nine-year old warmblood Polish Thoroughbred-Warmblood-mixed mare underwent a clinical examination due to mild colic. Rectal findings were normal but the left kidney was not palpable. The left nephrosplenic space was without the presence of large intestine. The remaining colic diagnostic and therapeutic procedures were carried out following the 
administration of analgesic and antispasmodic drugs $(0.2 \mathrm{mg} / \mathrm{kg}$ bw hioscinie-n-butylobromide with $25 \mathrm{mg} / \mathrm{kg} \mathrm{bw}$ dipyrone), resulting in the resolution of the pain symptoms. Due to the lack of a palpable left kidney in the rectal examination, the owners agreed to have the horse re-examined seven days later in order to perform a full urinary tract examination. The horse was clinically healthy: the temperature, heart and respiratory rates were within normal limits. The mucous membranes appeared normal, and the capillary refill time did not exceed two seconds. No erosive or ulcerative lesions or excessive dental tartar were diagnosed in the oral cavity. The body condition of the horse was rated as five on a nine-point scale. According to the owners, the horse was regularly vaccinated (against equine influenza and tetanus) and dewormed. Also the control blood tests carried out two years earlier by another veterinarian were within the reference range. The mare was stabled indoors, had access to a green pasture and was used recreationally. The owner did not observe any signs of systemic disease, appetite loss or problems during urination. According to the owner, the colic symptoms had not occurred again.

The rectal examination was repeated, and similarly to the previous examination, the left kidney was not palpable in its normal location. As expected, the right kidney and ureters were not palpable. The bladder was palpable and had an elastic wall. It did not appear painful and was moderately filled. A transcutaneous ultrasound scan of the left region of the abdominal cavity was performed using a MyLab ${ }^{\text {TM }}$ 30Gold VET scanner and a convex 1-4 MHz transducer (Esaote). It failed to localise the left kidney in its anatomical position. It was localised during systematic abdominal cavity scanning, between the middle and lower third of the abdominal cavity in the left flank, under the spleen, under the $L 1-L 2$ vertebrae. The kidney was more round in shape and smaller than normal, measuring $9.9 \times 6.8 \times 5.8 \mathrm{~cm}$. There was a poor corticomedullary differentiation and the internal echostructure was poorly defined (Fig. 1). It was difficult to determine the corticomedullary index. Due to the imaging-depth limit, Doppler signals of the renal vessels and the renal flow could not be obtained in comparison to the right kidney (Fig. 2). A comparative ultrasound examination of the right kidney, which was located anatomically to the right of the vertebral column in the 15th-17th intercostal space, was performed. The right kidney was heart-shaped. Its size $(12.2 \times 7.6 \times 6.1 \mathrm{~cm})$ and structure were normal and it had a physiological corticomedullary index. No renal pelvis dilation, tumours or cysts were identified in the kidneys. The ureters were not visible during the examination. After determining the location of the left kidney, the rectal examination was repeated. However, due to the presence of the colon, it was not palpated. The Edan DUS3Vet scanner and a rectal V561 $3-7 \mathrm{MHz}$ transducer were used to assess the urinary bladder, which appeared normal. Based on the results of the examinations, unilateral ectopy and hypoplasia of the left kidney were diagnosed in the mare. Functional urinary tract abnormalities were ruled out based on a control complete blood count (RBC 7.24T/I, WBC $7.1 \mathrm{G} /$, neu $5.1 \mathrm{G} / \mathrm{l}$, lym $1.7 \mathrm{G} / \mathrm{l}$, mon $0.3 \mathrm{G} / \mathrm{l}$, PLT $203 \mathrm{G} / \mathrm{l}, \mathrm{Hb} 7.1 \mathrm{mmol} / \mathrm{I}, \mathrm{PCV} 0.33$ I/I), serum biochemistry (AST 299 U/I, ALP 165U/I, GGT 8U/I, GLDH 5.9 U/I, CK $173 \mathrm{U} / \mathrm{l}, \mathrm{TBil} 19.4 \mathrm{umol} / \mathrm{l}, \mathrm{TP} 61 \mathrm{~g} / \mathrm{l}, \mathrm{ALB} 30 \mathrm{~g} / \mathrm{l}, \mathrm{Ca}$ $2.92 \mathrm{mmol} / \mathrm{l}, \mathrm{Mg} 0.68 \mathrm{mmol} / \mathrm{l}, \mathrm{Fe} 30.1 \mathrm{umol} / \mathrm{l}, \mathrm{Na}$ $137 \mathrm{mmol} / \mathrm{l}, \mathrm{Cl} 98.5 \mathrm{mmol} / \mathrm{l}$, glucose $5.3 \mathrm{mmol} / \mathrm{l}$, bile acids
$6.9 \mathrm{umol} / \mathrm{l}, \mathrm{K} 3.5 \mathrm{mmol} / \mathrm{l}$ ) (Köller et al. 2014) and complete urinalysis (dark yellow colour, s. g. 1.035, cloudy transparency, peculiar smell, $\mathrm{pH} 6.7$, protein $0.09 \mathrm{~g} / \mathrm{l}$, protein: creatini-
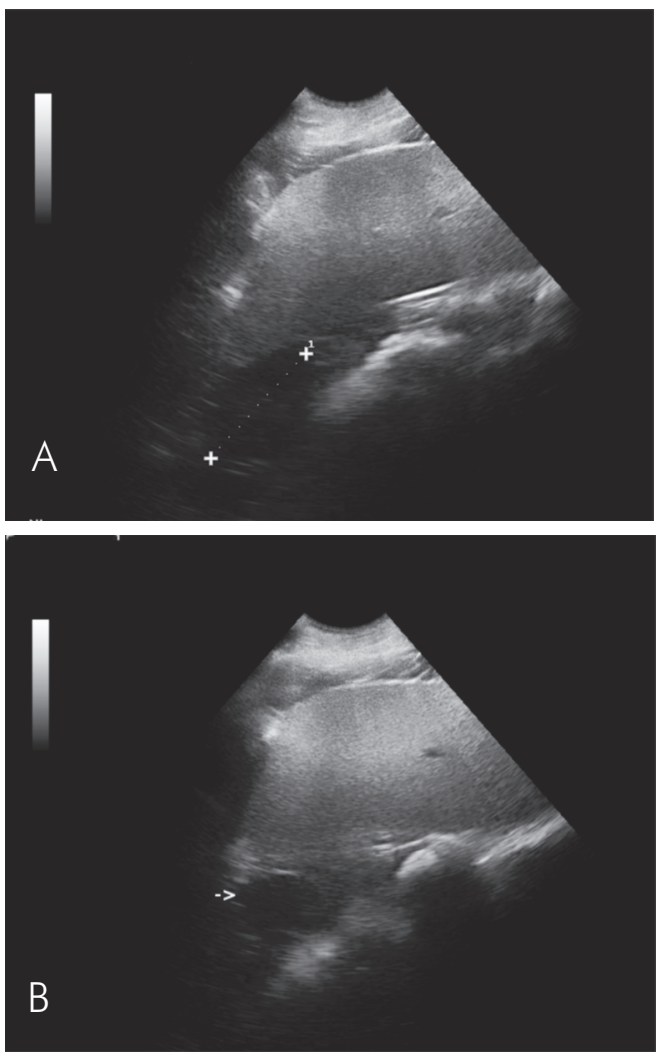

Fig. 1 Longitudinal (A) and transverse (B) ultrasound image of the mare's left kidney (A - white clips, B - white arrow), located deep beneath the spleen in the lower third of the abdominal cavity at the level of L1-L2 vertebrae. Visible architectural distortion and change of shape. In A picture also visible measurement of the length of the changed kidney.

Longitudinales (A) und transversales (B) Ultraschallbild von der linken Niere der Stute ( $A$ - weiße Klammern, B - weißer Pfeil), tief unter der Milz gelegen, im unteren Drittel der Bauchhöhle auf Höhe des L7-L2 Lendenwirbels. Sichtbare Verkrümmung der inneren Struktur und Veränderung der Gestalt. In Bild A ist auch die Bemessung der Länge (cm angeben!!) der veränderten Niere sichtbar.

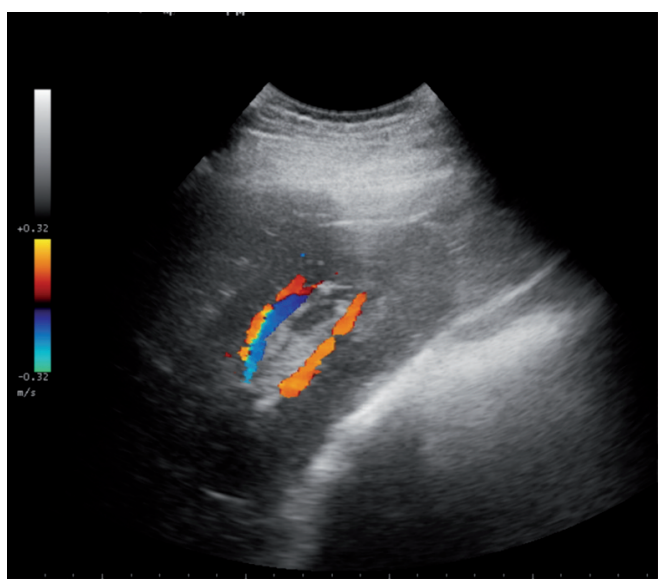

Abb. 2 Colour-Doppler ultrasound image of the mare's normal right kidney, located physiologically without changes in shape, size and architecture. Intrarenal blood vessels are clearly visible.

Farbdoppler-Ultraschallbild von der rechten Niere der Stute physiologisch angeordnet, ohne Veränderung der Gestalt, Größe und der inneren Struktur. Intrarenale Blutgefäße sind klar sichtbar. 
ne ratio 0.048 , moderate sediment, numerous carbonates calcium and monohydrate calcium oxalate) assessed from urine collected during natural micturition. The blood urea concentration was $4.2 \mathrm{mmol} / \mathrm{l}$, and the serum creatinine concentration was $102 \mathrm{umol} / \mathrm{l}$. The GGT-to-creatinine ratio as well as both blood and urine creatinine concentrations were within reference ranges. The owner did not agree to a kidney biopsy as there were no signs of renal failure, and the horse was in a good clinical condition. No treatment was initiated. Patient monitoring and annual blood examinations were advised. In case of any deterioration in the clinical state of the mare, additional tests were advised.

\section{Discussion}

In the presented case, the main anomaly was the location of the left kidney in the lower half of the abdominal cavity, whereas anatomically it is located in the paralumbar region and extends from the 15th-17th intercostal space to the L1-L2 vertebrae (Draper et al. 2012). Kidney ectopy is a congenital anomaly characterised by an abnormal organ position, leading to its undetectability in the rectal and ultrasonographic examination in its expected location. According to the adopted medical classification, kidney ectopia includes simple kidney ectopia, where the kidney and ureter remain on the correct side of the body, and the crossed kidney ectopia, where the kidney is located on the opposite side to the ureteric orifice (Ramanathan et al. 2016). In the presented case, it was not possible to localise the ureters and determine their course as they were impalpable in the rectal examination and not visible in ultrasound imaging. Ectopic kidneys may be located in the pelvic or abdominal cavity. They are usually smaller than the normally positioned kidneys, which has been described in mares (Ramanathan et al. 2016). The ureteral length depends on the kidney location. According to literature, kidney anomalies often accompany other urogenital abnormalities (Waldridge et al. 2009, Glodny et al. 2009, Gull et al. 2001). In the described mare, there were changes in the shape and size of the anomalous kidney. The approximate size of the kidney in Thoroughbreds has been determined at $15 \times 9 \times 8 \mathrm{~cm}$ (Draper et al. 2012), while in other breeds it may even reach $18 \times 15 \times 6 \mathrm{~cm}$ (Williams et al. 2014). A reduced kidney size may result from ectopia although changes in the kidney structure, such as thinning of the cortex and medulla, also suggest kidney hypoplasia (Andrews et al. 1986). Kidney hypoplasia is described as reduced organ size associated with its incomplete development. Renal hypoplasia and ectopia occur during embryonic development. In human medicine, kidney hypoplasia refers to a lack of more than $1 / 3$ of the kidney parenchyma, with substantially less medullary tissue (Gull et al. 2001).

Due to the fact that the ultrasound imaging features of renal disease are often unspecific, kidney hypoplasia should be differentiated from renal atrophy caused by pyelonephritis, chronic vascular disease or end-stage renal injury (Ramanathan et al. 2016). Renal atrophy may be distinguished based on an irregular kidney shape caused by scarring, in contrast to the smooth organ outline present in renal hypoplasia. In the studied mare, the ultrasound images of the kidney showed a normal organ border with a normal echogenic appearance, i.e. the renal cortical echogenicity was lower than that of the liver and spleen (Draper et al. 2012). Kidney dysplasia is usually associated with increased kidney echogenicity, caused by the presence of fibrous tissue (Ramirez et al. 1998). The characteristic features of renal dysplasia include architectural distortion, a lack of corticomedullary differentiation and small, compact kidneys. Such abnormalities are often accompanied by ureteral malformations, which were not assessed in the presented case. Chronic kidney disease is often associated with increased organ echogenicity, usually indicating the presence of a cellular infiltrate (Finn-Bodner 1995, Nyland et al. 1995, Wooldridge et al. 1999). Renal densities, a poorly defined internal structure and changes in the appearance of the renal pelvis are also frequently observed. In such cases, the kidneys are small and irregular. According to literature, it is assumed that reduced organ size, changes in ultrasonographic echogenicity and changes in the shape of the organ occur to secondary to other diseases, while architectural distortion indicates abnormal tissue differentiation (Finn-Bodner 1995, Woodridge et al. 1999, Rantanen 1986). In horses with chronic kidney disease, the kidneys are usually small, pale and have an irregular shape (Andrews et al. 1986). Based on the information provided by the owner as well as the clinical, blood and ultrasound examination, it may be assumed that the renal changes in the presented mare were congenital and did not result from urinary tract disease.

In previously described cases of congenital renal malformations in horses, the onset of clinical symptoms was usually observed in newborn animals, foals and young adult horses up to two years of age. Late-onset symptoms were described in a single seven-year-old horse (Gilday et al. 2015). Clinical symptoms of equine ureteral ectopia were observed within several months of life. However, some cases of incidentally diagnosed dysplasia, without biochemical changes, have also been reported (Ronen et al. 1993). Hence, congenital urinary defects may have different effects on the renal function. In most cases of developmental disorders, the clinical symptoms presented early and corresponded to the progressing renal failure (Andrews et al. 1986). Those symptoms included depression, lethargy, no weight gain or progressive weight loss, and the blood examination revealed azotaemia and electrolyte imbalances. In one horse, there were symptoms of colic (Waldridge et al. 2009). Urinary incontinence and its consequences were observed in some horses (Pringle et al. 1990, Waldridge et al. 2009). In the presented nineyear old mare, the incorrect kidney position and appearance did not give any clinical symptoms. As renal hypoplasia is not painful, the observed colic must have been caused by another reason. The congenital defect affected one kidney, and its function may have been preserved. In the cases where the healthy kidney compensates for the disorders of the other kidney, compensatory hypertrophy of that kidney is observed (Glodny et al. 2009). In the presented mare, the right kidney was not enlarged. Animals with complete loss of the hypoplastic kidney function developed signs of kidney dysfunction (Gull et al. 2001). In one case, bilateral renal dysplasia led to azotaemia following general anaesthesia. It was considered as a triggering factor despite the fact that the patient had no clinical symptoms or haematological signs of renal disease prior to surgery (Ramirez et al. 1998). Patients with urinary tract anomalies are more prone to renal failure, which is usually associated with a decreased functional capacity of the 
abnormal kidney. Glomerular degeneration, interstitial fibrosis and glomerulitis are considered to be secondary to congenital disorders, and are more pronounced in these animals. The prognosis in horses with bilateral urinary tract anomalies is guarded due to no compensatory mechanisms and earlier signs of kidney failure (Andrews et al. 1986). According to current knowledge, congenital urinary tract disorders usually occur plurally. They may be accompanied by disorders of other organs, especially those of the reproductive system (Waldridge et al. 2009). Animals with urinary tract anomalies are also more prone to other urinary tract diseases, such as urolithiasis (Gilday et al. 2015, Ramanathan et al. 2016, Wooldridge et al. 1999). Ectopic kidneys are also more susceptible to infections (Glodny et al. 2009). It is currently apparent that chronic renal failure cannot be fully cured. However, according to literature, the life expectancy of animals with congenital renal anomalies that develop clinical signs of renal failure can be prolonged by more than ten months while maintaining their quality of life (Plummer 2006).

Ultrasonography is a very useful non-invasive technique that can be used in the field and enables the detection of congenital urinary tract anomalies. Ultrasound imaging facilitates early diagnosis, patient monitoring, treatment planning and detecting complications associated with congenital kidney anomalies. In horses, kidney ultrasonography may be limited by the anatomic kidney position. Many of the ultrasound images obtained during the examination are unspecific. In some cases, it may be necessary to perform scintigraphy, especially if the examined organ is very small or covered by aerated lungs or gas in the intestinal loops (Ramanathan et al. 2016). In smaller animals, such as foals, contrast-enhanced computed tomography may also be useful (Gull et al. 2001). If there are structural changes within the kidney, a biopsy should be performed, and the collected specimen should be examined histopathologically. The limitation of the presented case is the absence of both of these procedures due lack of the owner's consent. Hence, the exact type and severity of parenchymal lesions could not be determined, and the diagnosis was based solely on the ultrasound examination.

The hereditary nature of congenital urinary tract anomalies has been determined in other species, such as dogs and pigs, but it has not been studied and determined in horses (Hoppe 1990, Maxie and Newman 2007, Paslawski et al. 2013). Some authors assume that teratogenic drugs (such as aminoglycosides and corticosteroids) administered to pregnant mares may lead to urinary tract anomalies in the offspring (Barr 1994, Hoppe 1990, Hulton and Kaplan 1995, Maxie and Newman 2007). Other causes of such anomalies may include uterine inflammation and systemic viral infections in pregnant mares (Maxie and Newman 2007). Further causes may include a failure of transfer of passive immunity, sepsis and preterm or immature birth, although these have not been confirmed scientifically (Brown et al. 1988, Jones et al. 1994, Naylor et al. 2009, Ramirez et al. 1998). To date there have been no reports assessing renal anomalies of the offspring of affected horses.

Renal anomalies diagnosed incidentally require further diagnostics to determine the renal function. These include a complete blood count (mostly the number of erythrocytes and
PCV), serum biochemistry and urine analysis to assess the total protein and the concentration of urea, creatinine and electrolytes. Kidney disease should be considered in young horses with a history of progressive weight loss, stunted growth and lethargy. If clinical symptoms occur at an early age, congenital urinary tract anomalies should be considered in the differentia diagnosis. If, on the contrary, the patient does not manifest any clinical symptoms of kidney disease, regular monitoring is essential in order to diagnose the failure of compensatory mechanisms of the healthy kidney. In one reported case of a complete loss of unilateral kidney function, kidney failure was diagnosed despite a normal ultrasound and computed tomography examination of the second, normal kidney (Gull et al. 2001).

\section{Statement of informed consent}

The owner has agreed to describe the clinical case and its publication in a medical journal.

\section{References}

Andrews F. M., Rosol T. J., Kohn C. W., Reed S. M., DiBartola S. P. (1986) Bilateral renal hypoplasia in four young horses. J. Am.Vet.Med. Assoc. 189, 209-212

Barr M. (1994) Teratogen update: angiotensin converting enzyme inhibitors. Teratology 50, 399-409

Brown C. M., Parks A. H., Mullaney T. P., Sonea I., Sickle R. L. (1988) Bilateral renal dysplasia and hypoplasia in a foal with an imperforate anus. Vet. Rec. 122, 91-92

Daneman A., Alton D. J. (1991) Radiographic manifestations of renal anomalies. Radiol. Clin. North. Am. 29, 351-363

Draper A. C. E., Bowen I. M., Hallowell G. D. (2012) Reference ranges and reliability of transabdominal ultrasonographic renal dimensions in Thoroughbred horses. Vet. Radiol. Ultrasound 53, 336-341; DOI 10.1111/j.1740-8261.2011.01902.x

Finn-Bodner S. T. (1995) Practical veterinary ultrasound. Cartee R. E., Williams \& Wilkins, Philadelphia

Gilday R. A., Wojnarowicz C., Tryon K. A., Lohmann K. L. (2015) Bilateral renal dysplasia, hydronephrosis, and hydroureter in a septic neonatal foal. Can. Vet. J. 56, 257-260

Glodny B., Petersen J., Hofmann K. J., Schenk C., Herwig R., Trieb T., Koppelstaetter C., Steingruber I., Rehder P. (2009) Kidney fusion anomalies revisited: clinical and radiological analysis of 209 cases of crossed fused ectopia and horseshoe kidney. BJU Int. 103, 224-235; DOI 10.1111/i.1464-410X.2008.07912.x

Gull T., Schmitz D. G., Bahr A., Read W. K., Walker M. (2001) Renal hypoplasia and dysplasia in an American miniature foal. Vet. Rec. 149, 199-203; DOI 10.1136/vr.149.7.199

Hoppe A. (1990) Progressive nephropathy due to renal dysplasia: a congenital kidney disease of several dog breeds. Svensk Vet. Tidn. 42, 399-402

Hulton S. A., Kaplan B. S. (1995) Renal dysplasia associated with in utero exposure to gentamicin and corticosteroids. American Journal of Medical Genetics 58, 91-93

Jones S. L., Longer D. L., Sterner-Kock A., Snyder J. R., Carlson G. $P$. (1994) Renal dysplasia and benign uteropelvic polyps associated with hydronephrosis in a foal. J. Am. Vet. Med. Assoc. 204, 1230-1234

Köller G., Gieseler T., Schusser G. F. (2014) Hämatologische und blutchemische Refenzbereiche bei Pferden unterschiedlicher Rasse und Altersgruppen basierend auf nevesten labordiagnostischen Methoden. Pferdeheilkunde 30, 381-393; DOI 10.21836/PEM 20140402

Maxie M. G., Newman S. J. (2007) Kennedy \& Palmer's pathology of domestic animals. Maxie M.G., Elsevier, Edynburg, 438-444 
Naylor R. J., Mair T. S., Last R. (2009) Severe hyperkalemia associated with renal dysplasia in a 2-day-old foal. Equine Vet. Educ. 21, 358-363

Nyland T. G., Mattoon J. S., Wisner E. R. (1995) Veterinary diagnostic ultrasound. Nyland T. G., Mattoon J. S. WB Saunders Co, Philadelphia

Paslawski R., Janiszewski A., Noszczyk-Nowak A., Nowacki D., Paslawska U. (2013) Polycystic kidney disease in white domestic pigs. EJPAU 16, art-04

Plummer P. J. (2006) Congenital renal dysplasia in a 7-month-old quarter horse colt. Vet. Clin. North. Am. Equine Pract. 22, 63-69; DOI 10.1016/i.cveq.2005.12.026

Pringle J. K., Ducharme N. G., Baird J. D. (1990) Ectopic ureter in the horse: Three cases and a review of the literature. Can. Vet. J. 31, 26-30

Ramanathan S., Kumar D., Khanna M., Al Heidous M., Sheikh A., Virmani V., Palaniappan Y. (2016) Multi-modality imaging review of congenital abnormalities of kidney and upper urinary tract. World J. Radiol. 8, 132-141; DOI 10.4329/wjr.v8.i2.132

Ramirez S., Williams J., Seahorn T. L., Blas-Machado. U. B., Partington B. P., Valdes M., McClure J. R. (1998) Ultrasound-assisted dia- gnosis of renal dysplasia in a 3-month-old Quarter Horse colt. Vet. Radiol. Ultrasound 39, 143-146

Rantanen N. W. (1986) Diseases of the kidneys. Vet. Clin. North. Am. Equine Pract. 2, 89-103

Ronen N., van Amstel S. R., Nesbit J. W., van Rensburg J. D. (1993) Renal dysplasia in two adult horses: Clinical and pathological aspects. Vet. Rec. 132, 269-270

Waldridge B. M., Lenz S. D., Hudson J., Rodriguez-Hurtado I. (2009) Multiple congenital urogenital abnormalities in a Tennessee Walking Horse colt. Equine Vet. Edu. 21, 315-318; DOI 10.2746/ $095777309 \times 422997$

Williams S., Cooper J. D., Freeman S. L. (2014) Evaluation of normal findings using a detailed and focused technique for transcutaneous abdominal ultrasonography in the horse. BMC Veterinary Research 10(Suppl 1), S5; DOI: 10.1186/1746-614810S1-S5

Wooldridge A. A., Seahorn T. L., Williams J., Taylor H. W., Oliver J. L., Kim D. Y., Vicek T. J. (1999) Chronic renal failure associated with nephrolithiasis, ureterolithiasis and renal dysplasia in a 2year-old Quarter Horse gelding. Vet. Radiol. Ultrasound 40, 361 364 